\title{
Causes of Floccules Formation in Hydro-Treated Lubricating Base Oil
}

\author{
Tao Huang1, Hong Gao ${ }^{2}$ and Xingguo Cheng ${ }^{3}$ \\ ${ }^{1}$ College of Resource and Environmental Science, Lanzhou University, Lanzhou, \\ ${ }^{2}$ Key Laboratory of Western China's Environmental Systems (Ministry of Education), \\ College of Resource and Environmental Science, Lanzhou University, Lanzhou, \\ ${ }^{3}$ Lanzhou Lubricating Oil RED Institute of PetroChina, Lanzhou, \\ P. R. China
}

\section{Introduction}

150BS bright oil is an important kind of high viscosity lubricating base oil. Its main used field is to modulate some oils, such as gas engine oil, gear oil, compressor oil and aircraft hydraulic oil et al. The amount of thickening oil can be reduced greatly using this component. However, only a few refineries can produce this kind of product in China because of the special requirements of raw material and its high investment etc.

150BS bright oil produced by Karamay Refinery is a new series of health-friendly products. In comparison with traditional solvent-refined base oil, it has many excellent characteristics, such as high viscosity index, low volatility loss, and low aromatic content (Galiano-Roth and Page, 1994). However, the hydro-treated base oil became hazy and emerged floccules in low temperature after the high-pressure hydrogenation unit running for a period. This disadvantage seriously impact on the practical application and marketable credit of this product. Thus, it is necessary to find out the reason for the forming of floccules in KH150BS and to find an effective means to overcome this problem.

In recent years, many studies have discussed the problem of deposition emerging in base oils at low temperatures. Singh et al. (1999) pointed out the question of the threedimensional structure of the network in gels and of the type of interactions between crystals. They discussed the changes of the morphology of the crystals under different rates of cooling. In addition, other research showed that needle-shaped crystals were formed during slow cooling under static conditions, while platelet-like crystals with amorphous solid appeared under flow conditions (Dirand et al., 1998). Srivastava et al. (1993) found that the solid-liquid and solid-solid thermally induced phase transitions occurring in petroleum waxes play a great role in deciding the appearance of waxes and the deposition of waxes as temperature decrease causes sedimentation course. Pederson et al. (1991) established a thermodynamic model for the prediction of gel formation. However, these investigations mainly focused on the morphological and thermal behavior of the crystals under cooling conditions. This study firstly analyzed the composition of floccules. Then it found the cause of floccules formation in KH150BS at low temperature from the floccules formation 
mechanism and processing of KH150BS. Finally, the influence of floccules on properties of oil was investigated.

\section{Experiment}

\subsection{Reagents and apparatus}

Silica gel (60-100 mesh) was purchased from the Qingdao Chemical and Engineering Plant (Qingdao, China). The $\mathrm{n}-\mathrm{C}_{12} \mathrm{H}_{26}$ to $\mathrm{n}-\mathrm{C}_{50} \mathrm{H}_{102} \mathrm{n}$-Paraffins were all chromatographic grade, and other reagents used in this experiment were all analytical grade, including the petroleum ether, isooctane, carbon tetrachloride, urea, benzene, diethyl ether, butanone, toluene, and isopropyl alcohol. The petroleum ether was purified using percolation through the silica gel.

The analysis of the carbon number distribution of the floccules was performed on a gas chromatography (GC) 2010 (Shimadzu Company, Japan); the hydrocarbon type between the floccules and filtrated oils was analyzed by a QP5050 gas chromatography - mass spectrometry (GC-MS; Shimadzu Company, Japan); molecular weights were obtained using a K7000 Vapor Pressure Osmometer (Knauer Company, Germany); all degrees of branching were collected using a Nexus 670 infrared spectrometer (Nicolet Company, USA). For the other properties of original and filtrated oils, the apparatus are as follows: cloud point, BSQ4D8K (Xi' an Jinghua Petrochemical Instruments Company, China); Pour point, CPP97-2 (CPP97-2 Company, France); freezing point, JH011208 (Xi'an Jinghua Petrochemical Instruments Company, China); Viscosity, HVM472 (Herzog Company, Germany); Aniline point, JSH2802 (Hunan Petrochemical Instruments Company, China) Oxidation stability, SYD-0193 (Wuhan Gelaimo Company, China) Antifoam, P643 (Normalab Analis Company, France).

The hydrotreated base oil sample (KH150BS) was provided by Karamay Refinery (Xinjiang Province, P. R. China).

\subsection{Experimental procedures}

\subsubsection{Separation of the floccules from KH150BS}

To separate the floccules from the KH150BS under low viscosity conditions conveniently, a method of solvent dilution and filtration was employed at low temperature. The detailed procedures were as follows: (1) The sample was diluted with an equal mass of a solvent made of a 1:1 mixture of butanone and toluene. (2) One container of the above solution was set in each of four cryostats whose temperature was previously set at $-5^{\circ} \mathrm{C},-10^{\circ} \mathrm{C},-15^{\circ} \mathrm{Cand}-$ $20^{\circ} \mathrm{C}$. (3) The samples were separated into filtrated residue substances and filtrates with a vacuum pump, a grit filter (G4, aperture $5 \mu \mathrm{m}-6 \mu \mathrm{m}$ ) and a filter flask. (4) The solvents in the filtrates were again obtained with a rotary evaporator at negative pressure and a small amount of solvent in the filtrated residues was vaporized on a water bath. Finally, the floccules and filtrated oils were obtained by a series of above procedures.

\subsubsection{Separation of $n$-paraffins from the floccules}

The urea was dried for 2 hours at $105^{\circ} \mathrm{C}$ and then ground. One gram of floccules was dissolved in 30 grams of petroleum ether; then a certain amount of urea and isopropyl 
alcohol were added. The suspension was stirred in a round-bottomed flask for certain time at the certain temperature. After filtering with suction and washing the filter three times with $30 \mathrm{ml}$ of petroleum ether, the mass was decomposed in hot water. The liberated hydrocarbon was dissolved up in $20 \mathrm{ml}$ of diethyl ether, and the diethyl ether layer was separated. The evaporation of the diethyl ether and the residual petroleum ether left nparaffins.

\section{Results and discussion}

\subsection{Separation of floccules from KH150BS}

The cloud point is the temperature at which haze was observed in the oil, and it can reflect the range of temperature when the floccules appeared. As is shown in Table 1, the pour point of $\mathrm{KH} 150 \mathrm{BS}$ was $16^{\circ} \mathrm{C}$; however, its cloud point was $12^{\circ} \mathrm{C}$, and it decreased to $10^{\circ} \mathrm{C}$ after the floccules were separated from $\mathrm{KH} 150 \mathrm{BS}$ at $-5^{\circ} \mathrm{C}$. As the experimental temperature decreased, the cloud point, pour point, and freezing point of filtrated oils obviously exhibited a decrease; the viscosity index of filtrated oils firstly decreased, but subsequently it increased to 84 . The results indicate that the floccules were effectively separated from KH150BS by employing a method of solvent dilution and filtration at low temperature, and the floccules had high freezing points.

\begin{tabular}{|c|c|c|c|c|c|c|c|}
\hline \multicolumn{2}{|c|}{ Items } & $\begin{array}{c}\text { KH150 } \\
\text { BS }\end{array}$ & I & II & III & IV & Test method \\
\hline \multicolumn{2}{|c|}{ Temperature $/{ }^{\circ} \mathrm{C}$} & & -5 & -10 & -15 & -20 & \\
\hline \multicolumn{2}{|c|}{ Floccules/wt.\% } & & 1.67 & 2.71 & 4.18 & 5.65 & \\
\hline Viscosity & $40^{\circ} \mathrm{C}$ & 595.1 & 580.4 & 532.2 & 531.5 & 507.4 & GB/T265-1988 \\
\hline$/ m m^{2} \cdot s^{-1}$ & $100^{\circ} \mathrm{C}$ & 32.70 & 31.82 & 30.01 & 30.57 & 29.65 & GB/T265-1988 \\
\hline \multicolumn{2}{|c|}{ Viscosity index } & 84 & 82 & 82 & 84 & 84 & $\begin{array}{c}\text { GB/T1995- } \\
1998\end{array}$ \\
\hline \multicolumn{2}{|c|}{ Cloud point $/{ }^{\circ} \mathrm{C}$} & +12 & -10 & -13 & -14 & -16 & $\begin{array}{c}\text { GB/T3535- } \\
1983\end{array}$ \\
\hline \multicolumn{2}{|c|}{ Pour point $/{ }^{\circ} \mathrm{C}$} & -16 & -18 & -21 & -24 & -30 & GB/T510-1983 \\
\hline \multicolumn{2}{|c|}{ Freezing point $/{ }^{\circ} \mathrm{C}$} & -17 & -20 & -23 & -25 & -31 & $\begin{array}{c}\text { GB/T6986- } \\
1986\end{array}$ \\
\hline
\end{tabular}

I, II, III and IV is experimental procedure at $-5^{\circ} \mathrm{C},-10^{\circ} \mathrm{C},-15^{\circ} \mathrm{C}$ and $-20^{\circ} \mathrm{C}$ respectively.

Table 1. The properties of KH150BS and filtrated oils.

Kane et al. (2003) found that gel formation appeared for very low amounts of crystals (around 1-2\%) when the oil was cooled under quiescent conditions. In such conditions, a colloidal network, which embodies the oil, is formed, and the whole dispersion becomes a gel. As shown in Table1, the lowest content of the floccules separated from KH150BS was $1.67 \%$, and the content of the floccules exhibited an increase with a decrease in the experimental temperature. This experimental result revealed the morphology of crystals 
formed in base oil during slow cooling under quiescent conditions. The common features of the morphology are the nuclei of crystals, which have the shape of discs and are a single molecule thick. The lateral extension of the nuclei depends on the crystallization conditions. Under quiescent conditions, the formation of extended, continuous lamellas is allowed, making a colloidal network, which covers the oil itself.

\subsection{Analysis of the composition of the floccules}

\subsubsection{Average molecular weight}

At lower temperature, the crystal growth depends largely on the molecular weight distribution, concentration of paraffinic component and the composition of the oil (Webber, 2001). The average molecular weights of the floccules, KH150BS and filtrated oils were firstly measured and the results were given in Table 2. From Table 2, it can be seen that the average molecular weight of the floccules was obviously higher than KH150BS and the corresponding filtrated oil, besides, the average molecular weight between the floccules and filtrated oil exhibited a decrease with a decrease of the experimental temperature. It indicate that its solubility decreased with an increase in average molecular weight of the floccules, so the floccules separated at higher experimental temperature were more difficult to dissolve in KH150BS. Webber (2001) pointed out that the hydrocarbon which had large molecular weight easily shaped crystals and deposited in the oil. Hence, it can be primarily concluded that the floccules were some hydrocarbon mixture which had larger average molecular weight and lower solubility compared with KH150BS.

\begin{tabular}{ccccccccccc}
\hline Item & KH150BS & $\mathrm{L}_{1}$ & $\mathrm{~L}_{2}$ & $\mathrm{~L}_{3}$ & $\mathrm{~L}_{4}$ & $\mathrm{~F}_{1}$ & $\mathrm{~F}_{2}$ & $\mathrm{~F}_{3}$ & $\mathrm{~F}_{4}$ & Test method \\
\hline Molecular weight & 590 & 582 & 569 & 562 & 532 & 819 & 726 & 631 & 617 & $\begin{array}{c}\text { SH/T0583- } \\
1994\end{array}$ \\
\hline
\end{tabular}

$\mathrm{F}_{1}, \mathrm{~F}_{2}, \mathrm{~F}_{3}$ and $\mathrm{F}_{4}$ is the floccules separated from $\mathrm{KH} 150 \mathrm{BS}$ at $-5^{\circ} \mathrm{C},-10^{\circ} \mathrm{C},-15^{\circ} \mathrm{C}$ and $-20^{\circ} \mathrm{C}$ respectively; $\mathrm{L}_{1}, \mathrm{~L}_{2}, \mathrm{~L}_{3}$ and $\mathrm{L}_{4}$ is the filtrated oil at $-5^{\circ} \mathrm{C},-10^{\circ} \mathrm{C},-15^{\circ} \mathrm{C}$ and $-20^{\circ} \mathrm{C}$ respectively.

Table 2. Average molecular weights of KH150BS, the floccules and filtrated oils.

\subsubsection{Carbon number distribution of the floccules}

\subsubsection{Separation of $n$-paraffins from the floccules}

The content of n-paraffins in the floccules was so low that the carbon number distribution of the floccules couldn't be directly obtained using GC. Bengen (1940) firstly found that urea had the interesting properties of forming solid complexes with straight-chain organic compounds. So the urea was selected for the separation of linear aliphatic compounds from the analogous branched and cyclic compounds by the complexes formation between urea and linear aliphatic compounds. Zimmerschied (1950) reported that formation of urea complexes was reasonably rapid at room temperature, where their stability was adequate for high recovery and convenient handling. Recovery of the components by heating or by stirring with water was practically quantitative. Hence, in this work, n-paraffins in the floccules were separated by above method and the detailed procedures were described in section 2.2.2. In addition, this work investigated the influence of each factor on the separation and the results are as follows: 
a. The impact of the urea

From Figure 1 (a), it can be seen the amount of n-paraffins separated from floccules increase with amount of urea increasing. When $m_{\text {urea }}$ : $m_{\text {KH150BS }}$ is more than 0.4 , the amount of $n$ paraffins has no obvious change with increase of urea. The excess urea can make complexation equilibrium move to the synthesis direction, thus the $m_{\text {urea }}: m_{K H 150 B S}$ is determined to be 0.6 in this study.

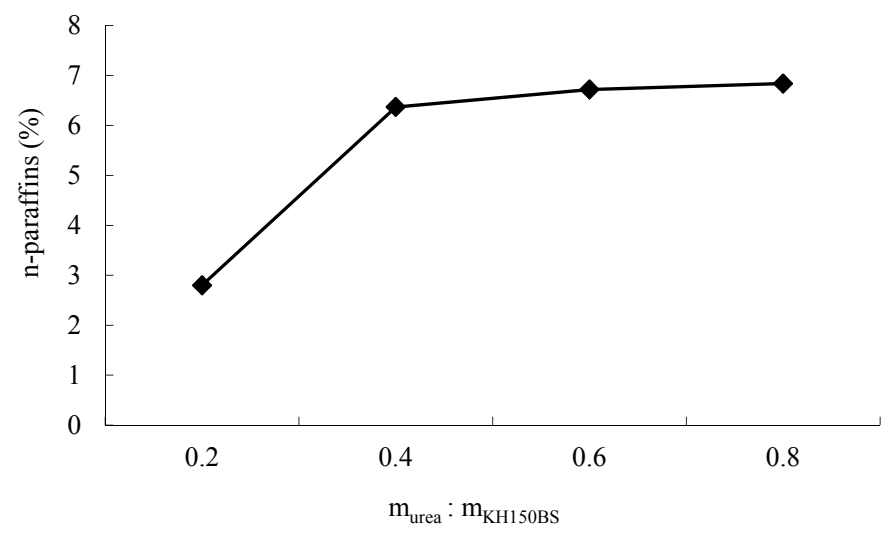

Fig. 1. (a) The impact of urea to separation of n-paraffins.

b. The impact of activator

The activator isopropyl alcohol will affect the reaction effect. If isopropyl alcohol is less, the viscosity of reaction system will be too large, which will lead urea and sample cannot be

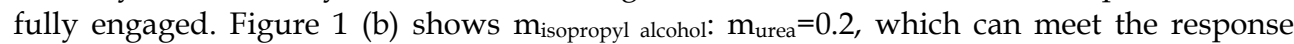
need. So this experiment determine $\mathrm{m}_{\text {isopropyl alcohol: }} \mathrm{m}_{\text {urea }}$ is 0.2 .

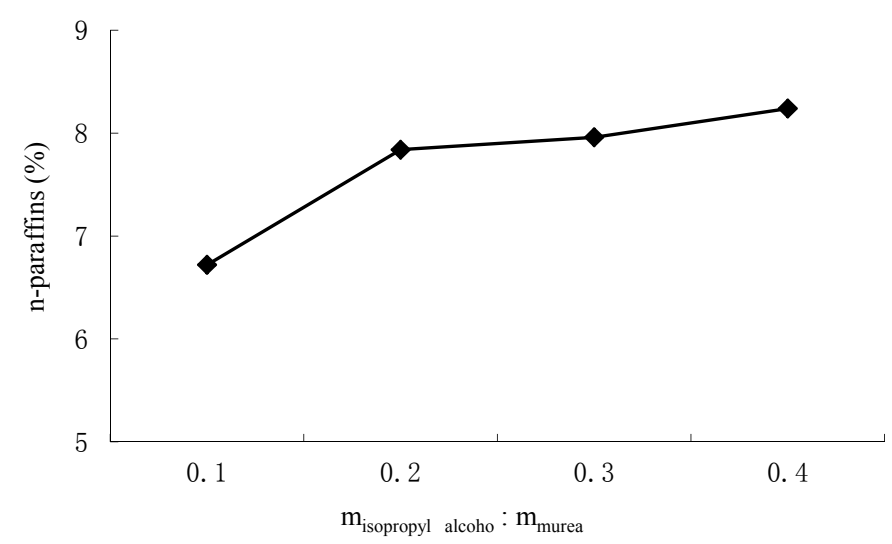

Fig. 1. (b) The impact of activator to separation of n-paraffins. 
c. The impact of reaction time

Figure 1 (c) is the relationship between the reaction time and content of n-paraffins and it shows when the reaction is 2 hours, the urea and n-paraffins has been completely complex. The content of n-paraffins has no obvious change with increasing of reaction hour after 2 hours. Therefore, it is determined the complex reaction time is 2 hours.

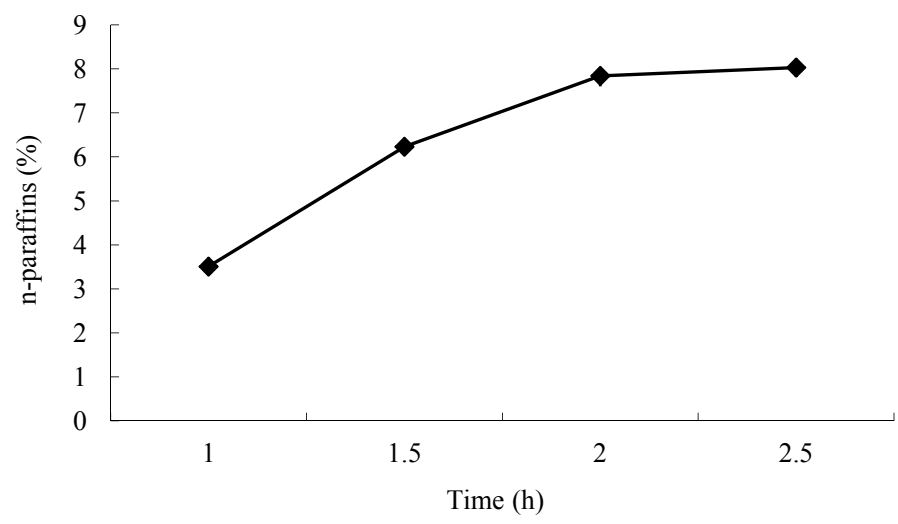

Fig. 1. (c) The impact of reaction time to separation of n-paraffins.

d. The impact of temperature

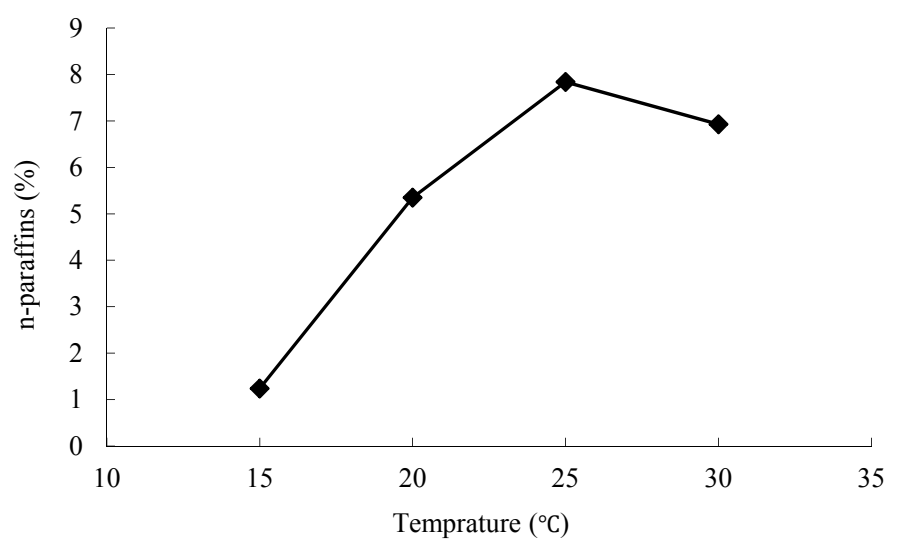

Fig. 1. (d) The impact of temperature to separation of n-paraffins.

The higher temperature can increase dissolving of each substance, decrease viscosity and improve the contact condition. However, the complex reaction is an exothermic reaction and lower temperature is conducive to this reaction. In addition, the higher temperature increases the stability of complexes and the content of n-alkanes will be reduced. From Figure $1(\mathrm{~d})$, it is determined the temperature was $25^{\circ} \mathrm{C}$. 


\subsubsection{Analysis of carbon number distribution of the floccules by GC}

The n-paraffins separated from the floccules at $-20^{\circ} \mathrm{C}$ were dissolved in isooctane $(0.01$ $\mathrm{g} / \mathrm{mL}$ ), then the carbon number distribution of paraffinic molecules in the floccules was obtained by GC and the result was shown in Figure 2. Srivastava et al. (1997) found that the amount of deposition was connected with the phase-transition parameters of the wax, which in turn depended on its composition and the carbon number distribution. Wang and Dong (1995) studied the influence of carbon number distribution on the pour point of several Chinese crude oils, and the results demonstrated that if the molecular weight of hydrocarbon is heavier, then the pour point of hydrocarbon is higher. In these particular cases, there was not a defined maximum in the carbon number distribution curve, and bimodal behavior was not observed in simulated distillation chromatograms. Holder and Winkler (1965) inferred that the pour point depression for an n-paraffins binary blend begins when the concentration of the low molecular weight compound is higher than $25 \mathrm{wt} \%$. However, a very small amount of the heavier paraffin was required to activate the light one. Del Carmen Garcia (2000) reported that the abundance of large n-paraffins (n $\mathrm{C} 24+$ ) in paraffinic crude oils increased their tendency to the wax crystallization, which could be demonstrated by a linear correlation between the concentration of this hydrocarbon family and the crude oil cloud point. The carbon number of paraffinic molecules present in deposits was known to be higher than 15 atoms and to reach values of more than 80 carbon atoms, as reported by several authors (O'Donell, 1951; Woo et al., 1984). However, as is shown in Figure 2, the greatest atomic number of the carbon atoms of the floccules separated from KH150BS was 47. This is because KH150BS is produced using hydro processing technologies entirely. In this process, some n-paraffins with longer chains and iso-paraffins with a lower degree of branching are hydro cracked and turned into paraffins with shorter chains and a higher degree of branching. In addition, the hydrocarbon compounds with longer alkyl chains easily form crystals at ambient temperature, and they cannot form crystal line adducts with urea (Bengen, 1940). As is shown in Figure 2, the nparaffins in the floccules had longer chains, the relative abundance of $\mathrm{n} \mathrm{C24+}$ paraffins was higher, and they easily formed crystals.

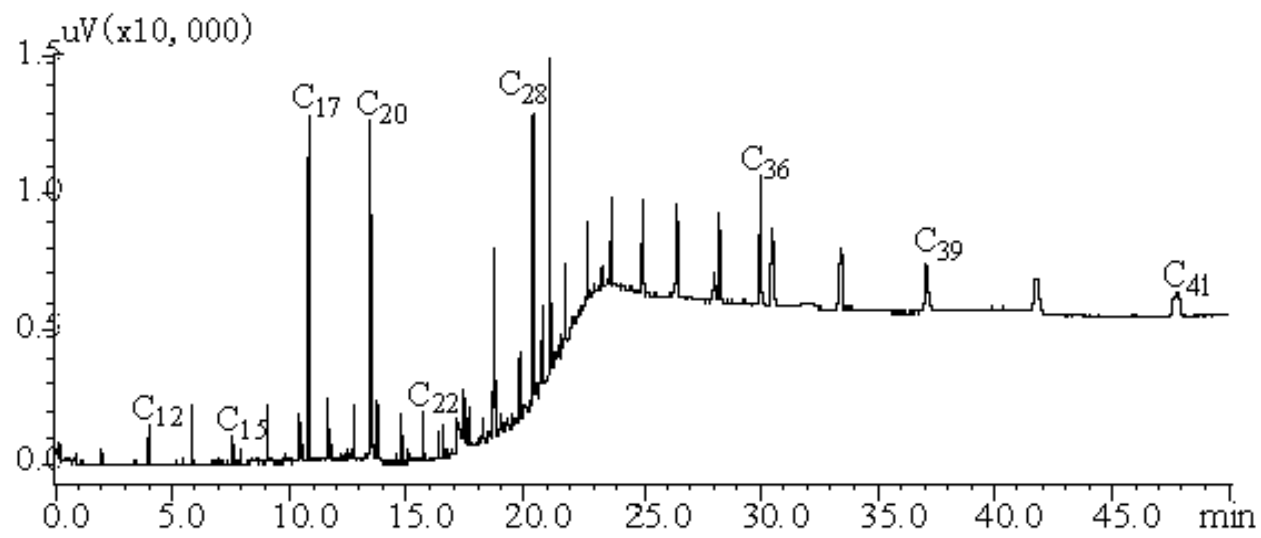

Fig. 2. Carbon number distribution of n-paraffins in the Floccules. 


\subsubsection{Hydrocarbon type of the floccules, KH150BS and filtrated oils}

The floccules, KH150BS and filtrated oils underwent a silica separation to yield saturates, aromatics and resins fractions through petroleum ether, benzene and ethanol washing off, respectively. Joao (1997) pointed out that the aromatic compounds didn't crystallize with paraffins nor changed their crystallization behavior. The concentration of aromatic compounds in KH150BS was approximately 5\%, in order to study the hydrocarbon type of the floccules, a method similar to ASTM D2786 was employed using GC-MS to analyze the saturates in the floccules, KH150BS and filtrated oils. The data of hydrocarbon type were given in Table 3.

Table 3 shows that there were some hydrocarbon compounds including a large amount of naphthenes except for some paraffins in the floccules. The content of paraffins in the floccules was higher than which in KH150BS and filtrated oils, in particular, the content of paraffins in the floccules separated at $-5^{\circ} \mathrm{C}$ was $18.6 \%$, which was higher than which in KH150BS by $6.85 \%$. However, the content of naphthenes in the floccules was lower than which in KH150BS and filtrated oils. In addition, with an increase in the content of the floccules, the concentration of paraffins in the filtrated oils slightly exhibited a decreased, for the floccules, the content of paraffins and mononaphthenes exhibited a decrease concomitant with an obvious increase in total naphthenes. This result is consistent with the report of the literature (Turner et al., 1955), namely, for the crystal formed in the $500^{\circ} \mathrm{C}+$ fractionation, it is composed of some naphthenes with longer side branch and lower ring numbers except for a number of paraffins with longer chain and lower degree of branching. Maria (2000) found that there was no change in the cloud point value when the concentration of cyclo+isoparaffins was lower than $40 \mathrm{wt} \%$, but cloud point of crude oil was increased when their concentration was greater than $50 \mathrm{wt} \%$. This increment in the cloud point was believed to arise as a consequence of the higher average molecular weight introduced by these components. From Table 3, it can be seen that the lowest concentration of naphthenes in the floccules was $77.36 \%$ and it could heighten cloud point of the oil.

\begin{tabular}{lccccccccc}
\hline Items & \multicolumn{10}{c}{ Concentration /wt. \% } \\
\cline { 2 - 10 } & $\mathrm{F}_{1}$ & $\mathrm{~F} 2$ & $\mathrm{~F}_{3}$ & $\mathrm{~F}_{4}$ & KH150BS & $\mathrm{L}_{1}$ & $\mathrm{~L}_{2}$ & $\mathrm{~L}_{3}$ & $\mathrm{~L}_{4}$ \\
\hline Paraffins & 18.6 & 16.39 & 15.61 & 15.31 & 11.75 & 10.79 & 10.25 & 10.07 & 9.7 \\
mono-ring & 15.75 & 14.01 & 13.87 & 13.79 & 12.39 & 11.1 & 13.11 & 12.9 & 11.04 \\
di-ring & 15.76 & 20.05 & 20.32 & 20.71 & 21.89 & 22.31 & 22.46 & 22.9 & 22.7 \\
tri-ring & 15.35 & 18.17 & 18.30 & 18.14 & 19.25 & 18.39 & 18.77 & 19.46 & 18.49 \\
tetra-ring & 16.49 & 17.02 & 16.78 & 16.56 & 18.04 & 19.43 & 17.32 & 16.83 & 18.69 \\
pent-ring & 9.05 & 9.35 & 9.62 & 9.88 & 10.39 & 11.3 & 11.49 & 10.83 & 11.88 \\
naphthenes & 77.36 & 78.57 & 78.89 & 79.05 & 81.91 & 82.48 & 83.14 & 82.97 & 82.8 \\
aromatics & 4.04 & 5.04 & 5.50 & 5.64 & 5.36 & 5.76 & 5.63 & 6 & 6.58 \\
resins & 0 & 0 & 0 & 0 & 0.98 & 0.97 & 0.98 & 0.96 & 0.90 \\
\hline
\end{tabular}

$\mathrm{F}_{1}, \mathrm{~F}_{2}, \mathrm{~F}_{3}$ and $\mathrm{F}_{4}$ is the floccules separated from $\mathrm{KH} 150 \mathrm{BS}$ at $-5^{\circ} \mathrm{C},-10^{\circ} \mathrm{C},-15^{\circ} \mathrm{C}$ and $-20^{\circ} \mathrm{C}$ respectively; $\mathrm{L}_{1}, \mathrm{~L}_{2}, \mathrm{~L}_{3}$ and $\mathrm{L}_{4}$ is the filtrated oil at $-5^{\circ} \mathrm{C},-10^{\circ} \mathrm{C},-15^{\circ} \mathrm{C}$ and $-20^{\circ} \mathrm{C}$ respectively.

Table 3. Hydrocarbon type of the floccules, KH150BS and filtrated oils. 


\subsubsection{Degree of branching of saturates in the floccules}

$\mathrm{Li}$ (1994) obtained some linear equations correlating the characteristic IR parameters to the $\eta_{\mathrm{CH}_{2}} / \eta_{\mathrm{CH}_{3}}$ (1/degree of branching) using the standard $n$-paraffins in a proper solvent. Subsequently, he established a method for determining $\eta_{\mathrm{CH}_{2}} / \eta_{\mathrm{CH}_{3}}$ of saturates in the petroleum wax by FTIR spectrometry. In this work, the above method was used to obtain $\eta_{\mathrm{CH}_{3}} / \eta_{\mathrm{CH}_{2}}$ of saturates in the floccules. The results were shown in Table 4.

$$
\eta_{\mathrm{CH}_{2}} / \eta_{\mathrm{CH}_{3}}=3.07 \times A_{1460} / A_{1380}-3.72
$$

Where $A_{1460}$ and $A_{1380}$ is absorbency of sample in the $1460 \mathrm{~cm}^{-1}$ and $1380 \mathrm{~cm}^{-1}$.

From Table 4, it is observed that the degree of branching of saturates in the floccules separated at $-5^{\circ} \mathrm{C}$ was lowest, and it increased with an increase in the content of the floccules. The results indicate that the degree of branching of hydrocarbon compound was lower, they were easier to increase wax crystallization. Ultimately, they formed deposition in the oil at low temperature.

\begin{tabular}{lllll}
\hline Items & $\mathrm{F}_{1}$ & $\mathrm{~F}_{2}$ & $\mathrm{~F}_{3}$ & $\mathrm{~F}_{4}$ \\
\hline$\eta_{\mathrm{CH}_{2}} / \eta_{\mathrm{CH}_{3}}$ & 7.23 & 4.26 & 2.90 & 2.91 \\
$\eta_{\mathrm{CH}_{3}} / \eta_{\mathrm{CH}_{2}}$ & 0.1383 & 0.2347 & 0.3448 & 0.3436 \\
\hline
\end{tabular}

$\mathrm{F}_{1}, \mathrm{~F}_{2}, \mathrm{~F}_{3}$ and $\mathrm{F}_{4}$ is the floccules separated from $\mathrm{KH} 150 \mathrm{BS}$ at $-5^{\circ} \mathrm{C},-10^{\circ} \mathrm{C},-15^{\circ} \mathrm{C}$ and $-20^{\circ} \mathrm{C}$ respectively;

Table 4. $\eta_{\mathrm{CH}_{3}} / \eta_{\mathrm{CH}_{2}}$ of saturates in the floccules.

\subsubsection{Carbon type between KH150BS and filtrated oils}

It was investigated that the viscosity index, pour point, oxidation stability, and other related properties of base oil depended on the composition and chemical nature of the aromatic, paraffinic, and naphthenic carbon contents (Yates et al., 1992). In this study, carbon types between KH150BS and filtrated oils were obtained using some base data of physical properties, and the method was similar to SH/T0729-2004. The results are shown in Table 5.

\begin{tabular}{cccccc}
\hline Items & KH150BS & L1 & L2 & L3 & L4 \\
\hline$n_{D}^{20}$ & & 1.4886 & 1.4886 & 1.4886 & 1.4886 \\
$\mathrm{M}$ & 0.8884 & 0.8885 & 0.882 & 0.8882 & 0.888 \\
$\mathrm{~S} / \mu \mathrm{g} \cdot \mathrm{g}^{-1}$ & 590 & 582 & 569 & 562 & 532 \\
$\mathrm{C}_{\mathrm{A}} \%$ & 70 & 73 & 70 & 69 & 73 \\
$\mathrm{C}_{\mathrm{N}} \%$ & 3.9148 & 3.9317 & 4.274 & 4.3528 & 4.848 \\
$\mathrm{C}_{\mathrm{P}} \%$ & 31.3017 & 31.601 & 31.405 & 31.5451 & 31.8893 \\
$\mathrm{R}_{\mathrm{A}}$ & 64.7835 & 64.4673 & 64.321 & 64.1021 & 63.2627 \\
$\mathrm{R}_{\mathrm{T}}$ & 0.2859 & 0.2834 & 0.3005 & 0.3022 & 0.3181 \\
$\mathrm{R}_{\mathrm{N}}$ & 3.2481 & 3.2308 & 3.1634 & 3.1408 & 3.0285 \\
\hline
\end{tabular}

$\mathrm{L}_{1}, \mathrm{~L}_{2}, \mathrm{~L}_{3}$ and $\mathrm{L}_{4}$ is the filtrated oil at $-5^{\circ} \mathrm{C},-10^{\circ} \mathrm{C},-15^{\circ} \mathrm{C}$ and $-20^{\circ} \mathrm{C}$ respectively.

Table 5. Carbon types of KH150BS and filtrated oils. 
Table 5 shows that the $C_{P}$ content of KH150BS was $64.78 \%$, which was higher than that of filtrated oils. However, the $\mathrm{C}_{\mathrm{N}}$ content was lower than that of filtrated oils. For the filtrated oils, the $C_{P}$ content exhibited a decrease with a decrease in experimental temperature. The results confirm that the floccules are composed of paraffins with lower degrees of branching and naphthenes having longer side branches and lower ring numbers.

$d_{4}^{20}$-Density $\left(20^{\circ} \mathrm{C}\right) / \mathrm{g} \cdot \mathrm{cm}^{-3} ; n_{D}^{20}$-Refractive index $20^{\circ} \mathrm{C}$; M-Average molecular weight; $\mathrm{C}_{\mathrm{A}^{-}}$ Content of carbon atoms in aromatic rings; $\mathrm{C}_{\mathrm{N}}$-Content of carbon atoms in naphthenes ring; $\mathrm{C}_{\mathrm{P}}$-Content of carbon atoms in paraffins; $\mathrm{R}_{\mathrm{A}}$-Average number of aromatic rings in every molecular; $\mathrm{R}_{\mathrm{T}}$-Average number of total rings in every molecular; $\mathrm{R}_{\mathrm{N}}$-Average number of naphthene rings in every molecular.

\subsection{Causes of floccules formation in hydro-treated lubricating base oil}

\subsubsection{Floccules formation mechanism}

In order to find the cause of floccules formation, it is important to study the floccules formation mechanism. Moussan (2004) thought at high temperatures, the crude oils containing linear paraffins behave like Newtonian liquids, the paraffins being in the molten state. Below the wax appearance temperature (WAT), which correspond to incipient crystallisation of the paraffins during cooling in static conditions, oils turning to gels. Sighn and Dirand (1999) pointed out the question of the 3D structure of the network in gels and of the type of interactions between crystals. They inferred that needle shaped crystals were formed during slow cooling under static conditions, while under flow conditions platelet like crystals with amorphous solid appear. Chanda (1998) thought the rheological behavior of a crude oil is highly influenced by its chemical composition, temperature and the current, as well as previous thermal history. High waxy crudes exhibit a non-Newtonian character, often with a yield stress at and below their pour point temperature. At a sufficiently high temperature the crude oil, although chemically very complex, is a simple Newtonian liquid. If the waxy crude oil is allowed to cool, wax will crystallize, agglomerate and entrap the oil into its structure. This phenomenon often happens if the ambient temperature of the place is below the pour point of the crude oil. In addition, two types of wax are commonly encountered in crude oils. The first is the macro crystal line wax composed of mainly straight-chain paraffins (n-alkanes) with varying chain length (about $\mathrm{C}_{20}-\mathrm{C}_{50}$ ). The second is the micro crystal line or amorphous waxes containing high portion of iso-parafins (cyclo alkanes) and naphthenes with a molecular weight ranges from $C_{30}$ to $C_{60}$. The presence of these solid particles causes a change in the flow behavior of crude oil from Newtonian to non-Newtonian (Rønningsen, 1991).

According to the analysis of section 2, the floccules were some hydrocarbon compounds with large average molecular weight, high paraffinic carbon content, and high freezing point. The floccules were composed of a large amount of naphthenes and some paraffins. The naphthenes had longer side branches and lower ring numbers, and the paraffins had longer chains and lower degrees of branching. During slow cooling under static conditions, these hydrocarbon compounds formed the nuclei of crystals, which had the shape of discs and were one molecule thick. Subsequently, the nuclei of crystals extended and became continuous lamellas. They formed acolloidal network and embodied the oil. Ultimately, they dispersed throughout the oil and formed the floccules. 


\subsubsection{The Impact of processing of KH150BS to floccules formation}

KH150BS produced by the lubricating oil high-pressure hydrogenation plant which includes hydrogenation process, hydro-dewaxing and hydrogenation refining. Hydrogenation process is characterized that the hydrogenation components, aromatics, especially polycyclic aromatic hydrocarbons are saturated by hydrogenation in the hydroprocessing catalyst, the polycyclic naphthenes are open-loop and generate a single cycloalkane ring or single ring aromatics with long side chains to. The aim of this process is to increase the viscosity index of lubricating oil. The hydro-dewaxing is a new technology for lubricating oil production. The wax in oil are removed or transformed by shape-selective catalysts by hydrocracking or hydroisomerization. Its aim is to decrease the pour point of lubricating oil. The hydrogenation refining process remove the sulfur, oxygen, nitrogen and other impurities, which is to improve the stability and color of oil.

By analyzing the process of KH150BS, it can be seen that the hydro-dewaxing process has the significant relationship between floccules formation. The hydrodewaxing process, the key factor is to choose an ideal catalyst. This catalyst should have good selectivity, which is able to make paraffins with high melting point (n-paraffin hydrocarbons and isoparaffins with less side-chain) cracking into low molecular weight alkanes, or change paraffins with high melting point to the paraffin hydrocarbon with low melting point by isomerization. Finally, the freezing point of lubricating oil is decreased and the ideal lubricant component is not destroyed in order to ensure a high oil yield. The catalyst used in KH150BS hydrodewaxing stage used is RDW-1 catalyst developed by Research Institute of Petroleum in China. It is a dual function of ZSM-5 zeolite loaded Ni catalyst. The Ni catalytic is used to hydrogenation and dehydrogenation, but the role of ZSM-5 zeolite is to provide a acid site and the shape-selective function.

The selectivity of zeolite is that zeolite separates the molecules of different sizes and shape by its effective diameter. In the mixed raw materials, only the molecules whose diameter are smaller than the aperture of zeolite can enter the zeolite pore channels within the active site and participate in the reaction as a reactant, and the molecules whose diameter are larger than the aperture of zeolite will be excluded from the zeolite pore and cannot participate the reaction.

The floccules are some hydrocarbons with large molecular weight and low degree of branching. This may be due to pore of catalyst become more and more narrow in the end of hydrogenation catalysts, some naphthenic isoparaffin and long-chain alkyl with large molecular weight cannot enter the pore of cracking catalyst and participate in the reaction, which cause the oil was observed hazy and emerged floccules at low temperatures.

\subsection{The Influence of floccules on properties of lubricating oils}

In order to investigate the influence of floccules on properties of oils, the properties of KH150BS and filtrated oils were shown in Table 6. It shows that, after floccules was removed using the low-temperature leaching method, the cloud point, pour point and freezing point of KH150BS obviously decreased. For other properties, compared with KH150BS, the viscosity and viscosity index of filtrated oils decreased, which is due to removal of floccules with long-chain. The aniline point of the filtrated oils slightly decreased compared with KH150BS. The aniline point is determined by hydrocarbons type and 
chemical composition of oils. In general, for different hydrocarbons with the same number of carbon atoms, aromatic is lowest and alkanes is highest. From Table 5, it can be seen that percentage content of aromatic carbon atoms in the filtrated oils are higher than which in KH150BS, which led the aniline point of the filtrated oils decreased. As the floccules are mainly some hydrocarbons with the longer carbon chain, the lower the degree of branching and they are easily be oxidized. Thus, the oxidation stabilities of the filtrated oils are higher than KH150BS. After removing floccules, the antifoams of filtrated oils have no obvious change except for at $24^{\circ} \mathrm{C}$. The antifoams of filtrated oils after removing floccules at $-5^{\circ} \mathrm{C}$ and $-15^{\circ} \mathrm{C}$ became $15 \mathrm{ml}$ and $25 \mathrm{ml}$ at $24^{\circ} \mathrm{C}$. This is because the viscosity of KH150BS is higher than filtrated oils. The viscosity is higher, the bubble floating is slower and it is more difficult to break. Thus, the antifoams of filtrated oils are better than KH150BS.

\begin{tabular}{|c|c|c|c|c|c|c|c|}
\hline \multicolumn{2}{|c|}{ Items } & KH150BS & $\mathrm{L}_{1}$ & $\mathrm{~L}_{2}$ & $\mathrm{~L}_{3}$ & $\mathrm{~L}_{4}$ & Test method \\
\hline \multicolumn{2}{|c|}{ Cloud point $/{ }^{\circ} \mathrm{C}$} & +12 & -10 & -13 & -14 & -16 & GB/T3535-1983 \\
\hline \multicolumn{2}{|c|}{ Pour point $/{ }^{\circ} \mathrm{C}$} & -16 & -18 & -21 & -24 & -30 & GB/T510-1983 \\
\hline \multicolumn{2}{|c|}{ Freezing point $/{ }^{\circ} \mathrm{C}$} & -17 & -20 & -23 & -25 & -31 & GB/T6986-1986 \\
\hline \multirow{2}{*}{$\begin{array}{l}\text { Viscosity } \\
\mathrm{mm}^{2} \cdot \mathrm{s}^{-1}\end{array}$} & $40^{\circ} \mathrm{C}$ & 595.1 & 580.4 & 532.2 & 531.5 & 507.4 & GB/T265-1988 \\
\hline & $100^{\circ} \mathrm{C}$ & 32.70 & 31.82 & 30.01 & 30.57 & 29.65 & GB/T265-1988 \\
\hline \multicolumn{2}{|c|}{ Viscosity index } & 84 & 82 & 82 & 82 & 84 & GB/T1995-1998 \\
\hline \multicolumn{2}{|c|}{ Aniline point $/{ }^{\circ} \mathrm{C}$} & 132.0 & 132.0 & 131.7 & 131.6 & 131.3 & ASTM D661 \\
\hline \multicolumn{2}{|c|}{$\begin{array}{l}\text { Oxidation stability(rotary } \\
\text { bomb oxidation } \\
\text { test, } 150^{\circ} \text { C) } / \min \end{array}$} & 41.1 & 42.2 & 41.8 & 42.6 & 43.7 & SH/T0193 \\
\hline \multirow{3}{*}{$\begin{array}{c}\text { Antifoam } \\
/ \mathrm{ml} / \mathrm{ml}\end{array}$} & $24^{\circ} \mathrm{C}$ & $90 / 0$ & $90 / 10$ & & $80 / 20$ & & \\
\hline & $93^{\circ} \mathrm{C}$ & $25 / 0$ & $25 / 0$ & & $30 / 0$ & & GB/T12579 \\
\hline & $24^{\circ} \mathrm{C}$ & $40 / 0$ & $15 / 0$ & & $25 / 0$ & & \\
\hline
\end{tabular}

Table 6. The properties of KH150BS and filtrated oils.

\section{Conclusions}

In this study, firstly, the floccules were effectively separated from KH150BS base oil and the composition and structure of the floccules were investigated in detail. Then the formation cause of floccules was analyzed from floccules formation mechanism and processing of KH150BS base oil respectively. Finally, the properties of KH150BS and the lubricating oils after removing floccules were investigated. The results indicate that the floccules were some hydrocarbon compounds with large average molecular weight, high paraffinic carbon content, and high freezing point. They were composed of a large amount of naphthenes and some paraffins. The naphthenes had longer side branches and lower ring numbers, and the paraffins had longer chains and lower degrees of branching. This may be due to the pore of catalyst become more and more in the end of hydrogenation catalysts, some naphthenic isoparaffin and long-chain alkyl with large molecular weight cannot enter the pore of cracking catalyst and participate in the reaction, which cause the oil was observed hazy and emerged floccules at low temperatures. During slow cooling under static conditions, these hydrocarbon compounds formed the nuclei of crystals, which had the shape of discs and were one molecule thick. Subsequently, the nuclei of crystals extended and became 
continuous lamellas. They formed a colloidal network and embodied the oil. Ultimately, they dispersed throughout the oil and formed the floccules. In addition, compared with KH150BS, the properties of the lubricating oils after removing floccules basically became better.

\section{References}

Bengen, Ger. Patent application O.Z. 12438 (March 18, 1940). Technical Oil Mission Reel 6, frames 263-70 (in German), and Reel 143, pp. 135-9 (in English).

Chanda, D., Sarmah, A., Borthakur, A. (1998). Combined effect of asphaltenes and flow improvers on the rheological behaviour of Indian waxy crude oil. Fuel. 77 (11): 1163-1167.

Del Carmen Garcia, M. (2000). Crude oil wax crystallization: The effect of heavy n-paraffins and flocculated asphaltenes. Energy \& Fuels. 14: 1043-1048.

Dirand, M., Chevallier, V., Provost, E., Bouroukba, M., and Petitjean, D. (1998). Multicomponent paraffin waxes and petroleum solid deposits : structural and thermodynamic state. Fuel. 77:1253-60.

Galiano-Roth, N., and Page, M. (1994). Effect of hydroprocessing on lubricant base stock composition and product performance. Lubrication Engineering. 50(8):659 -664.

Holder, G. A., and Winkler, J. (1965). Wax crystallization from distillate fuels. Part III. Effect of wax composition on response to pour depressant and further development of the mechanism of pour depression. J. Inst. Pet. 51(499): 243- 252.

Joao, A. P. Coutinho and Ve'ronique, R. M. (1997). Experimental Measurements and Thermodynamic Modeling of Paraffinic Wax Formation in Under cooled Solutions. Ind. Eng. Chem. Res. 36:4977-4983.

Kane, M., Djabourov, M., Volle, J-L., Lechaire, J-P., and Frebourg, G. (2003). Morphology of paraffin crystals in waxy crude oils cooled in quiescent conditions and under flow. Fuel. 82: 127-135.

Kane, M., Djabourov, M., Volle, J-L. (2004). Rheology and structure of waxy crude oils in quiescent and under shearing conditions. Fuel. 83: 1591-1605.

Morphology of paraffin crystals in waxy crude oils cooled in quiescent conditions and under flow. Fuel. 82:127-135.

Li, X. R., and Jiang, F. R. (1994). Determination the Ratio of Methylene to Methyl Group of the Saturate Fraction in Petroleum Wax by FTIR Spectrometry. Petroleum Refinery and Chemical Industry. 25:54-57.

Maria del Carmen Garcia. (2000). Crude Oil Wax Crystallization. The Effect of Heavy nParaffins and Flocculated Asphaltenes. Energy \& Fuels. 14:1043-1048.

O'Donell, G. (1951). Separating Asphalt into Its Chemical Constituents. Anal Chem. 23 (6):894.

Pederson, K. S., Skovborg, P., and Ronningsen, H. P. (1991). Wax Precipitation from North Sea Crude Oils. 4. Thermodynamic Modeling. Energy and Fuels. 5:924.

Rønningsen, H. P., Bjørndal, B., Hansen, A. B., Pedersen, W. B. (1991). Wax precipitation from North Sea crude oils. 1. Crystallization and dissolution temperature, and Newtonian and non-Newtonian flow properties. Energy and Fuels. 5: 895-908.

Singh, P., Fogler, H.S., Nagarajan, N. (1999). Prediction of the wax content of the incipient wax-oil gel in a pipeline: An application of the controlled-stress rheometer. J Rheol. 43:1437-59. 
Srivastava, S. P., Handoo, J., Agrawal, K. M., and Joshi, G.C. (1993). Phase-transiti- on studies in n-alkanes and petroleum-related waxes-A review. Journal of the Physics and Chemistry of Solids. 54:639.

Srivastava, S. P., Saxena, A. K., Tandon, R. S., and Shekher, V. (1997). Measurement and prediction of solubility of petroleum waxes in organic solvents. Fuel. 76(7):625- 630.

Turner, W. R., Brown, D. S., and Harrison D. V. (1955). Properties of Paraffin Waxes Composition by Mass Spectroometer Analysis. Ind Eng Chem. 47(6):1219.

Wang, B., and Dong, L.D. (1995). Paraffin characteristics of waxy crude oils in China and the methods of paraffin removal and inhibition. Paper SPE 29954, SPE International Meeting on Petroleum Engineering, Beijing, China. November 14-17, 33-48.

Webber, R. M. (2001). Yield Properties of Wax Crystal Structures Formed in Lubricant Mineral Oils. Ind. Eng. Chem. Res. 40:195-203.

Woo, F. T., Garbis, S. J., and Gray, T. C. (1984). Paper SPE 13126, presented at the 59th Annual Fall Technical Conference and Exhibition, Houston,TX.

Yates, N. C., Klovsky, T. E., and Bales, J. P. (1992, August). In Symposium on Processing, Characterisation and Applications of Base Oils, Division of Petroleum Chemistry, American Chemical Society, Washington, D C.

Zimmerschied, W. J., Dinerstein, R. A., Weitkamp, A. W., and Marschner, R. F. (1950). Crystalline Adducts of Urea with Linear Aliphatic Compounds. Ind Eng Chem. 42:1300-1306. 


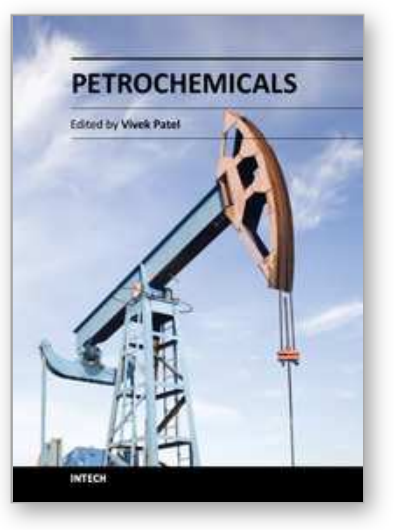

\author{
Petrochemicals \\ Edited by Dr Vivek Patel
}

ISBN 978-953-51-0411-7

Hard cover, 318 pages

Publisher InTech

Published online 28, March, 2012

Published in print edition March, 2012

The petrochemical industry is an important constituent in our pursuit of economic growth, employment generation and basic needs. It is a huge field that encompasses many commercial chemicals and polymers. This book is designed to help the reader, particularly students and researchers of petroleum science and engineering, understand the mechanics and techniques. The selection of topics addressed and the examples, tables and graphs used to illustrate them are governed, to a large extent, by the fact that this book is aimed primarily at the petroleum science and engineering technologist. This book is must-read material for students, engineers, and researchers working in the petrochemical and petroleum area. It gives a valuable and costeffective insight into the relevant mechanisms and chemical reactions. The book aims to be concise, selfexplanatory and informative.

\title{
How to reference
}

In order to correctly reference this scholarly work, feel free to copy and paste the following:

Tao Huang, Hong Gao and Xingguo Cheng (2012). Causes of Floccules Formation in Hydro-Treated Lubricating Base Oil, Petrochemicals, Dr Vivek Patel (Ed.), ISBN: 978-953-51-0411-7, InTech, Available from: http://www.intechopen.com/books/petrochemicals/causes-of-floccules-formation-in-hydro-treated-lubricatingbase-oil

\section{INTECH}

open science | open minds

\author{
InTech Europe \\ University Campus STeP Ri \\ Slavka Krautzeka 83/A \\ 51000 Rijeka, Croatia \\ Phone: +385 (51) 770447 \\ Fax: +385 (51) 686166 \\ www.intechopen.com
}

\author{
InTech China \\ Unit 405, Office Block, Hotel Equatorial Shanghai \\ No.65, Yan An Road (West), Shanghai, 200040, China \\ 中国上海市延安西路65号上海国际贵都大饭店办公楼405单元 \\ Phone: +86-21-62489820 \\ Fax: $+86-21-62489821$
}


(C) 2012 The Author(s). Licensee IntechOpen. This is an open access article distributed under the terms of the Creative Commons Attribution 3.0 License, which permits unrestricted use, distribution, and reproduction in any medium, provided the original work is properly cited. 